\title{
The Contribution of Social Rank and Attachment Theory to Depression in a Non Clinical Sample of Adolescents
}

\author{
Sylvia Pinna Puissant ${ }^{1}$, Jean-Marie Gauthier ${ }^{1}$, and Robin Van Oirbeek ${ }^{2}$ \\ ${ }^{1}$ Université de Liège (Belgium) \\ ${ }^{2}$ Katholieke Universiteit Leuven (Belgium)
}

\begin{abstract}
This study explores the relative contribution of the overall quality of attachment to the mother, to the father and to peers (Inventory of Parent and Peer Attachment scales), the style of attachment towards peers (Attachment Questionnaire for Children scale), the social rank variables (submissive behavior and social comparison), and sex and age variables in predicting the depression score (Center of Epidemiological Studies Depression Scale) on a non-psychiatric sample of 13-18 year old adolescents $(n=225)$. Results of our integrated model (adjusted R-Square of .50) show that attachment variables (overall quality of attachment to the father and to the mother), social rank variables (social comparison and submissive behavior), age and sex are important in predicting depressive symptoms during adolescence. Moreover, the attachment to peers variables (quality of attachment to peers, secure and ambivalent style of attachment) and sex are mediated by the social rank variables (social comparison and submissive behavior).

Keywords: depression, adolescence, social rank, attachment, adolescents.
\end{abstract}

En este estudio se explora la contribución de la calidad general del apego a la madre, al padre y a los iguales (Inventario de Apego con Padres y Pares); el estilo del apego a los iguales (Cuestionario de apego para niños); variables de rango social (conducta sumisa y comparación social); y las variables de género y edad como predictoras de depresión (Escala de Depresión del Centro de Estudios Epidemiológicos) en una muestra no psiquiátrica de adolescentes de 13 a 18 años de edad $(n=225)$. Los resultados del modelo propuesto (R-cuadrado ajustado de .50) indican que las variables de apego (calidad general de apego al padre o la madre), las variables de rango social (comparación social y conducta sumisa), así como la edad y el género, son importantes a la hora de predecir síntomas depresivos durante la adolescencia. Más aún, las variables de apego hacia los iguales (calidad del apego a los iguales, estilo de apego seguro y ambivalente) y el género, están influenciadas por variables de rango social (comparación social y conducta sumisa).

Palabras clave: depresión, adolescencia, rango social, apego, adolescentes.

This research was supported by the grant "Non FRIA" of the Research Council of the Liège University awarded to Sylvia Pinna Puissant. We would like to thank Dr. Leon Sloman and Dr. John Price for their valuable suggestions.

Correspondence concerning this article should be addressed to Sylvia Pinna Puissant, Département Psychologies et cliniques des systèmes humains, Boulevard du Rectorat, 3 (B33) 4000 Liège, Belgium. E-mail: sylviapinna@gmail.com 
The third principal cause of mortality among young people worldwide is suicide, with Europe having the highest levels. This is in one way or another associated with depression (World Head Organization [WHO], 2005). Crosssectional studies of adolescent self-reported depressive symptoms indicate that approximately 20 to $50 \%$ of adolescents report significant subsyndromal levels of depression (Hankin, 2006). These rates are comparable across different cultures, e.g., Mexico (Leyva-Jiménez, HernándezJuárez, Nava-Jiménez, \& López-Ganoa, 2007), Turkey (Eskin, Ertekin, Harlak, \& Dereboy, 2008), and France (Chabrol, Rodgers, \& Rousseau, 2007). The frequency is clearly higher for girls and tends to increase over the years (e.g., Ge, Lorenz, Conger, Elder, \& Simons, 1994; Rushton, Forcier, \& Schetman, 2002). In summary, these findings clearly show that there is a high prevalence of depression in the adolescent population. Understanding the mechanisms that may underpin the presence of depression in this developmental age appears to be critical.

According to Stevens and Price (2000), psychopathology such as depression can appear whenever the basic needs for individual development are not provided for by the social and physical environment. Two of these basic needs are the need for status or rank and the need for attachment. Therefore, a frustration or an inappropriate activation of at least one of these two elements can give rise to depression.

The social rank theory focuses on social power in relationships (dominant versus submissive behavior) and on judgments of one's relative standing (concerning inferiority or incompetency). The theory proposes that depressive symptoms are a response to losing rank and to a conception of oneself as a loser. Depression occurs when one begins to see oneself as a hopeless liability, and when one feels that the group would be better off without one and that one is, consequently, in grave danger of being disliked (Stevens \& Price, 2000). This is in accordance with the sociometer theory (Leary, 2003), which states that certain psychological problems are caused in one way or another by insufficient acceptance.

A low social rank mainly manifests itself as feeling inferior and subordinate to others. As such, social rank consists of two prominent dimensions, i.e., the cognitive dimension characterized by social comparison (perceptions of personal superiority or inferiority), and the behavioral dimension characterized by submissive behavior (inhibition in situations of challenge or conflict), (Gilbert \& Allan, 1994).

Adolescents are extremely sensitive to social comparisons and to their perception of their social status (rank) in relation to their peers. Consequently, negative interpersonal experiences, such as being humiliated and devalued by others (e.g., through bullying) are strongly related to a low selfesteem, since they lead to threats to social acceptance, approbation and belonging (Leary, 2003; Sloman, 2008). This social defeat not only causes severe stress and a forced submissive behavior (i.e., when one perceives the situation as being impossible to change or escape from; Gilbert, 2000), but it also leads to poor mental health (Rigby, Slee, \& Martin, 2007) and to depression (Aslund, Nilsson, Starrin, \& Sjöberg, 2007).

The need for attachment or the need for "searching and maintaining proximity with another individual" also influences our emotional reactions and affects (Bowlby, 1969). The attachment system, as developed by the primary caregivers (mostly the parents) during childhood, has a threat-safeness function, and depression can occur when the attachment system is less efficient. This means that safe and supportive environments reduce tension and anxiety (secure attachment). When such a safe environment cannot be established, the attachment system is less efficient and one is more worried about rejection and more focused on social comparisons (insecure attachment) (Irons \& Gilbert, 2005; Sloman, Gilbert, \& Hasey, 2003). As such, insecurely attached individuals may interpret negative interpersonal events in terms of personal unworthiness and incompetence, which may, in turn, contribute to the development of depressive symptoms (Margolese, Markiewicz, \& Doyle, 2005, Sund \& Wichstrom, 2002). Therefore, a good quality of attachment to parents can offer the adolescent a context favorable to the management of negative emotions, which allows the adolescent to better tolerate strange and potentially stressful situations and to use behavioral strategies adapted to those situations (Duchesne \& Larose, 2007).

Since peers have an important place during adolescence, a complementary role between attachment to parents and to peers has been suggested (Nickerson \& Nagle, 2005). It has been shown that the perception of a good quality of attachment to parents and to peers (as measured by The Inventory of Parent and Peer Attachment - IPPA) is related to good mental health (Armsden \& Greenberg, 1987), to an adequate social and emotional capacity (Laible, 2007) and to the psychological adjustment of the adolescent (Wilkinson, 2004). Also, Young, Berenson, Cohen, and Garcia (2005) state that peer support and parental support together with their interaction constitute significant factors in the prediction of depressive symptoms.

A general shortcoming in all these studies is that the attachment to the father and to the mother was evaluated as one unique combined variable. This does not allow the identification of the relative contribution of the different attachment figures (Doyle, Lawford, \& Markiewicz, 2009) with the development of depression. This is particularly the case since paternal and maternal attachment both contribute to the adolescent's social functioning and adjustment in overlapped or distinct domains, e.g., the father being more influential in relation to the young person's self-worth (Dekovic \& Meeus, 1997), friend support (Doyle et al., 2009), social expectation of peer interaction and depressive symptoms and the mother being more influential in the adolescent's family support (Liu, 2008). Therefore, in our study, the quality of attachment to the father, to the mother and to peers was included separately. 
Based on the work of Ainsworth, Blehar, Waters, and Wall (1978), it was observed that individuals react differently in the way they handled stress according to specific strategies (secure, avoidant and ambivalent) for regulating attachment behavior. These strategies, which first evolve during infancy in the context of caregiver exchanges, persist across time and are generalized to a range of situations and experiences that evoke negative emotions (Cooper, Shaver, \& Collins, 1998). These patterns may explain how the person organizes his/her interactions and emotional experiences (Hazan \& Shaver, 1987) and why adolescents with a secure attachment towards their peers present a significantly lower level of depression than adolescents with an avoidant or ambivalent attachment towards their peers (Irons \& Gilbert, 2005). This indicates that taking different styles of attachment into account allows one to observe different ways of regulating, displaying and experiencing emotions.

In conclusion, the literature clearly shows that a failure of the attachment and social rank systems is related to the presence of depression. Nevertheless, the afore-mentioned studies were performed by taking into account either the social rank system or the attachment system. However, since each person evaluates his/her own social rank mainly within the context of his/her actual and past close relationships (Gilbert, Allan, \& Trent, 1995) and since studies show that parental attachment influences social interaction patterns with others (Dekovic \& Meuss, 1997; Laible, 2007; Wilkinson, 2004), an integrated model is proposed here that combines systematically both the attachment and social rank systems (Sloman et al., 2003; Sloman, 2008). This integrated model states that attachment and social rank have a complementary relationship, since a secure attachment is related to a good functioning of the dominance and subordination systems (social rank) and an insecure attachment (anxious and avoidant) is related to low levels of social competence (Cooper et al., 1998). Therefore, an individual who has a secure attachment, meaning that he or she benefits from good support and the comfort of an attachment figure, will develop feelings of self-worth, since the quality of attachment appears to be intimately related to how we judge ourselves (Wilkinson, 2004). As a result, the individual can accept defeat more easily, and this may facilitate the development of satisfactory relationships with peers (Dekovic \& Meuss, 1997). These satisfactory relationships with peers also contribute to a high self-worth, which will help the individual to manage negative emotions and therefore influence psychological symptoms (Wilkinson, 2004).

A first attempt to look at the relationship between peer attachment and social rank was provided by Irons and Gilbert (2005) in a non clinical sample of adolescents: secure attachment to peers was found to be positively related to a positive social comparison, negatively related to a submissive behavior (measures of social rank) and negatively related to depressive and symptoms of anxiety. These associations showed that secure attachment is related to a positive social rank, and insecure attachment to a feeling of inferiority and to the presence of submissive behavior, i.e., the more an adolescent feels inferior in relation to his or her group, the more he/she presents depressive symptoms. Moreover, submissive behavior constitutes a predictive factor of depression in adolescence (Öngen, 2006).

Our objective is to do more than to simply replicate the study of Irons and Gilbert in a different population, but to add more information. Therefore, an integrated model is proposed that not only incorporates the same measurements as in the work of Irons and Gilbert, i.e., the styles of attachment (secure, avoidant and ambivalent) towards peers and the social rank variables (social comparison and submissive behavior), but also other measures such as the quality of attachment to the mother, to the father and to peers (IPPA). We include this last measure, as the literature suggests observation of the effect of the attachment of each of the figures independently in order to predict depression during adolescence. The proposed integrated model could allow us to answer the following important research questions:

- Does social rank (social comparison and submissive behavior) still play a role in the prediction of depressive symptoms in our integrated model?

- What is the specific impact of the quality of attachment to the mother, to the father or to peers (as measured by the IPPA scales) in the prediction of depressive symptoms in our integrated model?

- How will the different styles of peer attachment (secure, ambivalent and avoidant) relate to depression in our integrated model?

- Finally, do sex and age remain important predictors in our integrated model, which takes into account predictors for attachment and social rank?

\section{Method}

\section{Participants}

Our study consisted of a sample of 225 French speaking adolescents (63 boys, 162 girls), aged between 13 and 18 years $(\mathrm{Med}=15.67, I Q R=1.83)$, attending the $1^{\text {st }}(1.78 \%)$, $2^{\text {nd }}(5.33 \%), 3^{\text {rd }}(43.56 \%), 4^{\text {th }}(28.00 \%) 5^{\text {th }}(17.33 \%)$ or the $6^{\text {th }}(4.00 \%)$ year. Of all the public secondary schools in the Liège area - Belgium, only 9 accepted to participate. Authorization to conduct research in the participating schools was granted by the school director. A document was sent home explaining the purpose of our research. Only the adolescents, from who a written informed consent from their parents and themselves was received, were enrolled in the study. Participants completed a set of self questionnaires in their own classrooms in the presence of their class teacher. 
The Ethical Committee of the Psychology Faculty approved the study.

\section{Measures}

The Center for Epidemiological Studies Depression Scale (CES-D). Developed by Radloff (1977), this scale evaluates the depressive symptomatology in a general population over the past week and contains 20 items (e.g., "My sleep was restless", "I felt that everything I did was an effort") ranging from 0 (rarely or none all the time) to 3 (most or all the time). The total score ranges from 0 to 60 . This scale is considered as a clinical screening instrument. According to Chabrol et al. (2002), a total score of 24 or more would indicate the presence of a possible major depressive disorder. Cronbach's alpha as reported by those authors was .85. In our sample, Cronbach's alpha was equal to .92 .

The Adolescent Social Comparison Scale-Revised (ASCSR). Adapted for adolescents by Paul Gilbert (Irons \& Gilbert, 2005), this scale measures whether the adolescent shows a positive or a negative social comparison in relation to his/her friends through 10 items (e.g., "Compared to your friends, how confident do you feel?") ranging from 1 (less confident) to 10 (more confident). The total score ranges from 10 to 100. A high total score represents a positive social comparison. Cronbach's alpha as reported by Irons and Gilbert (2005) was .66; in the present study, it was equal to .70.

The Adolescent Submissive Behaviour Scale (ASBS). Adapted for adolescents by Paul Gilbert (Irons \& Gilbert, 2005), this scale of 12 items evaluates the submissive choice of reaction in potential 'conflict' situations. The items (e.g., "I do things because others are doing them, rather than because I want to") ranged from 1 (never) to 5 (always). The total score ranges from 12 to 60 . Irons and Gilbert (2005) reported an internal consistency of .77. In our sample, Cronbach's alpha was equal to .80 .

The Inventory of Parent and Peer Attachment (IPPA), developed by Armsden and Greenberg (1987) in 3 versions: attachment to the mother, attachment to the father and attachment to peers. The inventory evaluates the quality of attachment through items that measure Trust, Communication and Alienation. Each of the 3 versions consists of 25 items (e.g., "I tell my mother about my problems and troubles", "I don't get much attention from my father", "My friends listen to what I have to say") ranging from 1 (almost never or never true) to 5 (almost always or always true). To obtain the overall score, all the items have to be summed after reversing the score of the items from the alienation subscale. A high score reflects a positive quality of attachment. High test-retest reliability over a 3 -week period has been reported: $r=.93$ for the parents and $r=.86$ for peers (Armsden \& Greenberg, 1987). In our sample, Cronbach's alpha on the father's attachment scale was equal to .78 , on the mother's attachment scale it was equal to .78 , and on the peer's attachment scale it was equal to .79 .
The Attachment Questionnaire for Children (AQ-C). Adapted by Sharpe et al. (1998) for children and adolescents. This questionnaire identifies through 3 descriptions the attachment style towards peers as: secure, avoidant or ambivalent. The descriptions are (a) "I find it easy to become close friends with other children. I trust them and I am comfortable depending on them. I do not worry about being abandoned or about another child getting too close friends with me" (i.e., secure attachment); (b) "I am uncomfortable to be close friends with other children. I find it difficult to trust them completely, difficult to depend on them. I get nervous when another child wants to become close friends with me. Friends often come more close to me than I want them to" (i.e., avoidant attachment); (c) "I often find that other children do not want to get as close as I would like them to be. I am often worried that my best friend doesn't really like me and wants to end our friendship. I prefer to do everything together with my best friend. However, this desire sometimes scares other children away" (i.e., ambivalent attachment). A Likert-based scoring system is used, which provides two measures (categorical and dimensional measures) for each of the attachment styles. Thus, participants select which of the 3 descriptions most accurately describes them, and also mark on a scale the degree to which each description is like them.

\section{Results}

\section{Descriptive statistics}

Using the cut-off score of 24 from the CES-D scale, we can tentatively conclude that $18.22 \%$ of the high school adolescents $(N=41 ; 32$ girls, 9 boys) may suffer from a major depressive disorder. Note that, in our sample, a higher number of girls $(N=32)$ had a CES-D score higher than 24 than did the boys $(N=9)$ and that our sample consisted of more girls $(N=162)$ than boys $(N=63)$. This suggests that the percentage of $18.22 \%$ might be the result of this gender imbalance rather than being representative of the rate of having a major depressive disorder in the French speaking Belgian population. In order to check for this, a Fisher's Exact Test was performed, showing that there is no significant difference in the proportion of girls versus boys with a CES-D score of more than $24(p=.34)$. This indicates that the rate of adolescents with a major depressive disorder $(18.22 \%)$ is not strongly affected by this gender imbalance.

Regarding the categorical choice of attachment style in the AQ-C scale, $77.16 \%(N=152)$ of adolescents perceived themselves as securely attached to their peers, $11.17 \%(N$ $=22)$ as avoidant and $11.68 \%(N=23)$ as ambivalent.

Significant sex differences were found for the sum scores of the CES-D scale, for the two social rank scales ASCS$\mathrm{R}$ and ASBS, and for the quality of attachment to peers (IPPA) scale. More specifically, boys have in general a lower 
Table 1

Descriptive statistics and two sample tests for sex differences

\begin{tabular}{lccccccc}
\hline Variable & \multicolumn{3}{c}{ Boys } & \multicolumn{3}{c}{ Girls } & \multicolumn{2}{c}{$p$} \\
& $M d n$ & $I Q R$ & Min-Max & Mdn & IQR & Min-Max \\
\hline Age & 15.61 & 2.16 & $13.1-17.8$ & 15.69 & 2.71 & $13.44-18.24$ & .641 \\
CES-D & 11 & 11 & $0-45$ & 13 & 14 & $0-52$ & $.049 *$ \\
ASCS-R & 66 & 15 & $23-84$ & 61 & 12 & $32-93$ & $.023 *$ \\
ASBS & 24 & 12 & $10-46$ & 27 & 9 & $10-49$ & $.004 * *$ \\
IPPA mother & 105 & 18 & $52-125$ & 105 & 23 & $33-125$ & .456 \\
IPPA father & 92 & 31 & $47-124$ & 91 & 26 & $34-123$ & .997 \\
IPPA peers & 97 & 21 & $54-120$ & 104.5 & 15 & $59-125$ & $.001 * *$ \\
AQ-C secure & 5 & 2 & $4-7$ & 4 & 3 & $1-7$ & .160 \\
AQ-C avoidant & 1 & 1 & $1-6$ & 1 & 1 & $1-7$ & .905 \\
AQ-C ambivalent & 2 & 2 & $1-7$ & 1 & 2 & $1-7$
\end{tabular}

Note. CES-D : The Center for Epidemiological Studies Depression Scale; ASCS-R : The Adolescent Social Comparison Scale-Revised; ASBS : The Adolescent Submissive Behaviour Scale; IPPA : The Inventory of Parent and Peer Attachment; AQ-C : The Attachment Questionnaire for Children.

Due to the asymmetric nature of some variables, the Median $(M d n)$ and Inter Quartile Range (IQR) were used as the measure of location and the measure of spread. For the symmetrically distributed variables the mean equals the median.

$* p<.05 . * p<.01$.

CES-D depression score, a lower level of submissive behavior (ASBS), a lower quality of attachment to peers (IPPA peers) and a more positive social comparison (ASCS$\mathrm{R})$. Descriptives for all the variables and the $p$-values of the Mann-Whitney $U$ test are presented in Table 1.

\section{Regression analysis}

In order to check for the relative contribution of the quality of attachment to the mother, to the father and to peers (IPPA scales), the style of attachment towards peers (AQ-C secure, AQ-C avoidant and AQ-C ambivalent, i.e., dimensional measures for each attachment style), the social rank variables (submissive behavior and social comparison), and sex and age variables in predicting the depression score (CES-D scale), a multiple regression analysis was performed consisting of all these variables together.

The residuals were normally distributed by using the square root of the depression score of the CESD scale. We obtained a final and significant model $(F(12,225)=17.28$, $p<.001)$ with an adjusted $\mathrm{R}$ square of .50 . From all the variables included in the model, quality of attachment to the father (IPPA father), $F(1,225)=47.26, p<.001$, quality of attachment to the mother (IPPA mother) and its interaction with age, $F(2,225)=4.43, p=.013$, social comparison and its interaction with submissive behavior, $F(2,225)=$ $4.16, p=.017$, submissive behavior and its interaction with social comparison, $F(2,225)=4.92, p=.008$, age and its interaction with quality of attachment to the mother (IPPA
Table 2

Results of the multiple regression of depression sum score on the attachment to parents and to peers and social rank sum score variables

\begin{tabular}{lrrr}
\hline Effect & \multicolumn{1}{c}{$B$} & $S E B$ & $\beta$ \\
\hline Intercept & 21.260 & 6.655 & $3.229^{* *}$ \\
Sex & .528 & .171 & $.417^{* *}$ \\
Age & -1.087 & .408 & $-.103^{* *}$ \\
IPPA mother & -.154 & .062 & $-.137^{*}$ \\
Age* IPPA mother & .009 & .004 & $.188^{*}$ \\
IPPA father & -.031 & .004 & $-.625^{* *}$ \\
IPPA peers & -.007 & .007 & -.094 \\
ASCS-R & .039 & .021 & -.088 \\
ASBS & .132 & .045 & $.150^{* *}$ \\
ASCS-R*ASBS & -.002 & .001 & $-.188^{*}$ \\
AQ-C secure & -.074 & .047 & -.113 \\
AQ-C avoidant & .018 & .052 & .047 \\
AQ-C ambivalent & .068 & .049 & .063 \\
\hline
\end{tabular}

Note. IPPA : The Inventory of Parent and Peer Attachment; $A S C S-R$ : The Adolescent Social Comparison Scale-Revised; $A S B S$ : The Adolescent Submissive Behaviour Scale; $A Q-C$ : The Attachment Questionnaire for Children.

${ }^{*} p<.05{ }^{* *} p<.01$.

mother), $F(2,225)=3.29, p=.040$ and sex, $F(1,225)=$ $9.48, p=.002$ have a $p$-value lower than .05 , meaning that these variables influence the depressive symptoms score. 
The beta weights, observed in Table 2, show that the CES-D depression score increases when the quality of attachment to the father decreases and that the CES-D depression score is (on average) higher for girls than for boys. The interaction effect between social comparison and submissive behavior is shown in Figure 1a. In this plot, the predictive effect of the submissive behavior scale on the CES-D scale is plotted out for a negative, a median and a positive social comparison. When the social comparison is negative, the CES-D depression score depends strongly on the value of the submissive behavior, attaining higher levels for the CES-D score as the submissive behavior increases. This relationship persists but diminishes for a median social comparison and practically disappears for a positive social comparison. In the latter case, the CES-D score is practically unaffected by the value of the submissive behavior. The interaction effect between quality of attachment to the mother (IPPA mother) and age is shown in Figure $1 \mathrm{~b}$. In this plot, the predictive effect of the quality of attachment to the mother on the CES-D scale is plotted out for different ages, i.e., 13, 14, 15 and 16. For a 13year old adolescent, the CES-D depression score decreases as the quality of attachment to the mother increases. As the adolescent becomes older, the effect of the quality of attachment to the mother on the CES-D score diminishes, as can be seen for the ages of 14 and 15, and even disappears for 16-year old adolescents. Moreover, it can be observed that on average the depressive score increases as age increases.

\section{Mediation analysis}

In Irons and Gilbert (2005), social comparison and submissive behavior were both found to be mediators for the AQ-C ambivalent scale; and social comparison was found to be a mediator for the AQ-C avoidant scale. Since this study is a partial replication of the study of Irons and Gilbert (2005), this mediation analysis (Figure 2) was repeated using multiple regression models.

We started by checking whether the predictor variables, i.e., the quality of attachment measures (IPPA father, IPPA mother and IPPA peers), the style of attachment towards peers (AQ-C secure, AQ-C avoidant and AQ-C ambivalent), sex and age, are mediated by the two social rank variables (ASCS$\mathrm{R}$ and ASBS) in the prediction of the dependent variable (CESD). Step 1 of the analysis found that the predictor variables produced a significant model $(F(9,225)=21.01, p<.001$, adjusted R square of .47). Step 2 showed that the predictor variables impacted significantly on both social comparison $(F(9,225)=7.82, p<.001$, adjusted $\mathrm{R}$ square of .231) and submissive behavior $(F(9,225)=10.24, p<.001$, adjusted $\mathrm{R}$ square of .289), respectively. Step 3 of the analysis examined whether the hypothesized mediators are related to the dependent variable, when controlling for the predictor variables. Again, a significant model was produced $(F(12,225)=17.59, p<$ .001 , adjusted R square of .498). Analysis of the standardized beta weights indicated that both social comparison and submissive behavior partially mediated the relationship between sex, quality of attachments to peers and AQC-ambivalent a

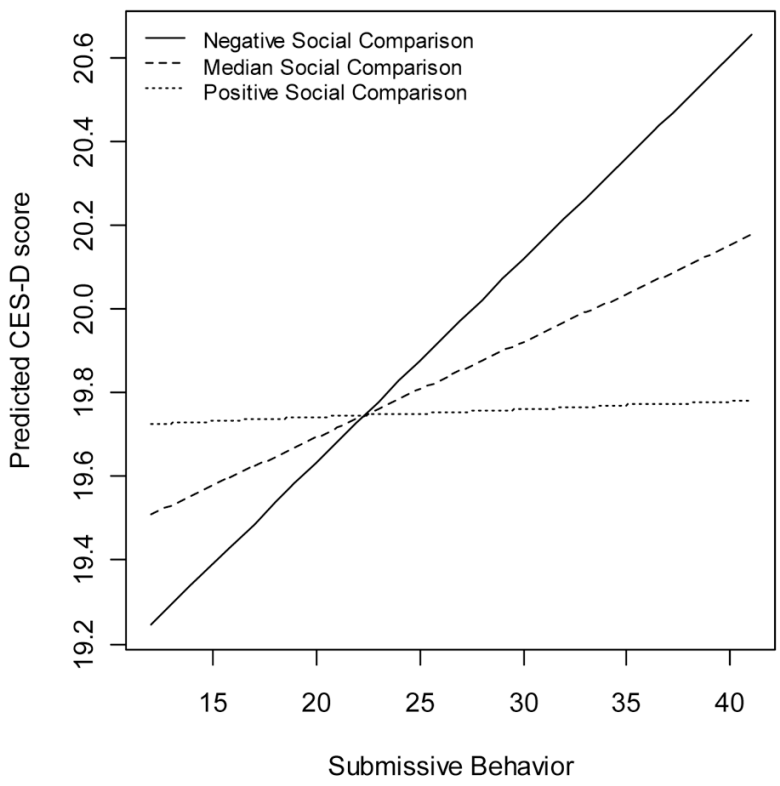

b

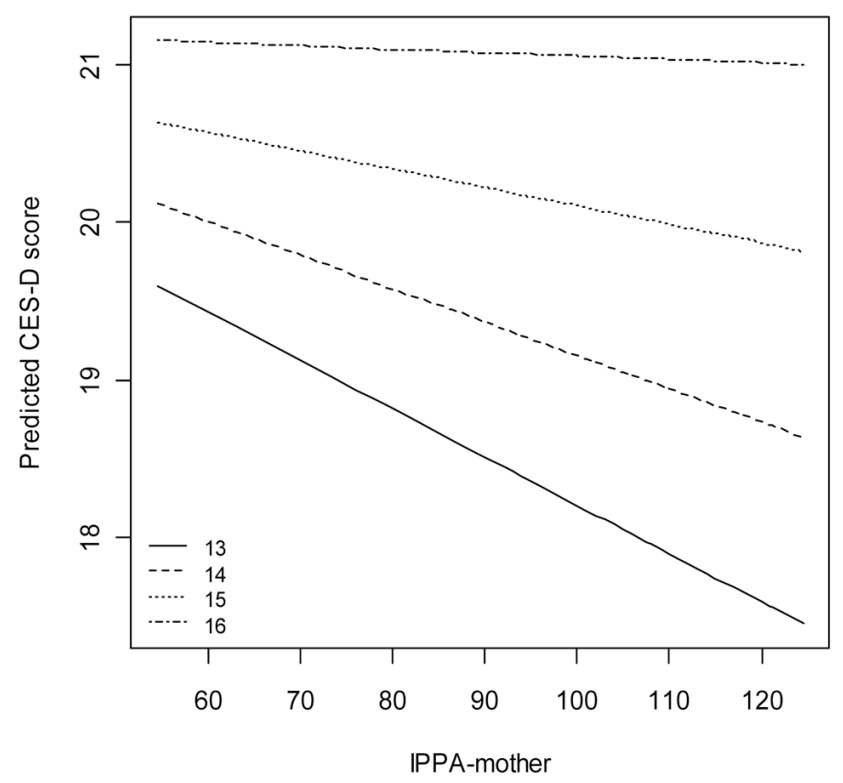

Figure 1. Interaction effects on the CES-D depression score; $\mathrm{a}=$ Social comparison and submissive behavior; $\mathrm{b}=\mathrm{Quality}$ of attachment to the mother (IPPA-mother) and age. 

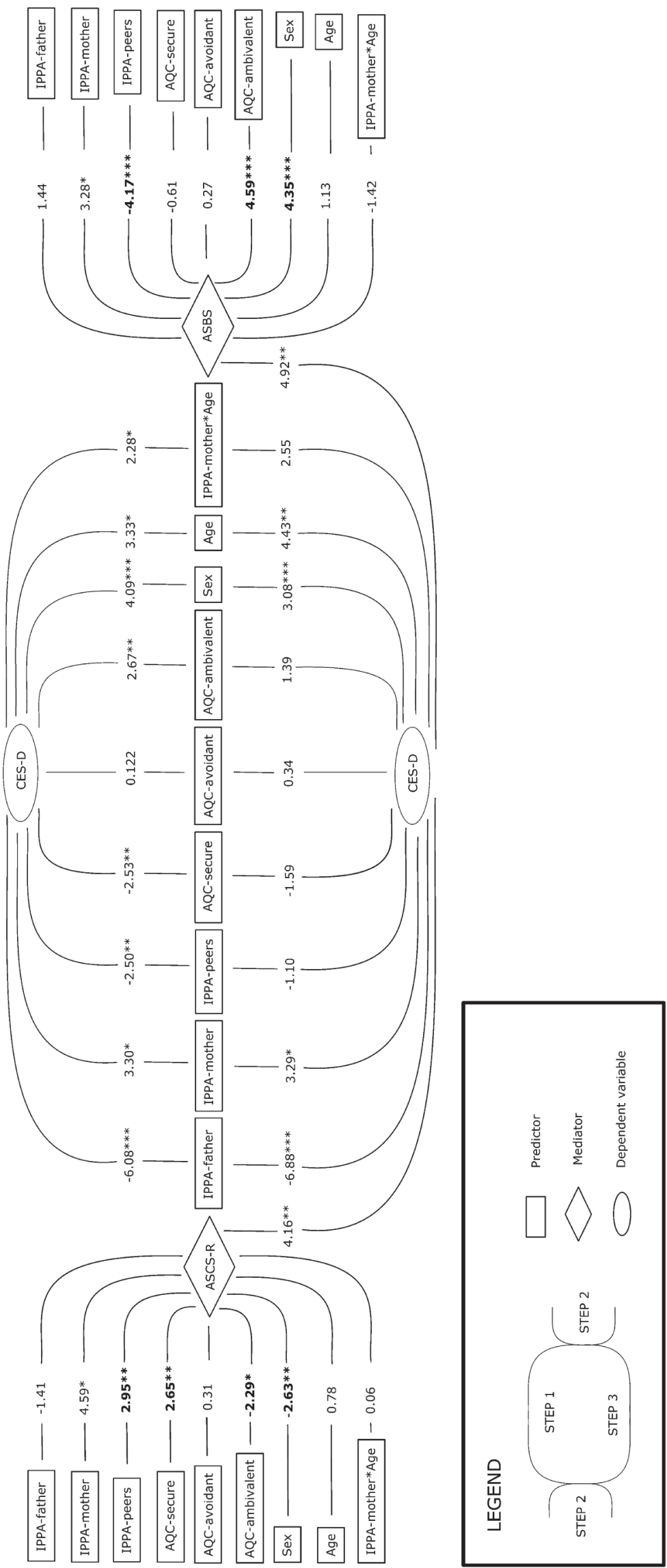
and depressive symptoms. AQC-secure was partially mediated by the social comparison measure.

This shows that a more ambivalent attachment style towards peers and/or a lower quality of attachment to peers results in a more negative social comparison and in a higher level of submissive behavior, and that a more secure attachment style towards peers results in a more positive social comparison. Moreover, girls have on average a more negative social comparison and a higher level of submissive behavior than boys, thereby indicating how social comparison and submissive behavior partially mediated the variable of sex. Note that sex still has a significant direct relationship with depression, even when accounting for the potential mediating effects of the social rank scales.

\section{Discussion}

In our sample, $18.22 \%$ of secondary school adolescents may have a major depressive disorder. This percentage does not differ significantly from the worldwide rates in adolescent depression including Europe (e.g., results of Chabrol et al., 2007 on French adolescents). In addition, the distribution of our sample into the different attachment styles (secure, avoidant, ambivalent) towards their peers (AQ-C), does not differ significantly from the results of Irons and Gilbert (2005) in high school students in Great Britain, indicating a good consistency of our data.

Based on the research of Irons and Gilbert (2005) and Sloman (2008), the main aim of our research was to explore the relative contribution of social rank scales (social comparison and submissive behavior), quality of attachment to the mother, to the father and to peers independently from each other (IPPA), styles of attachment towards peers (secure, avoidant and ambivalent), age and sex in an integrated model for the prediction of depressive symptoms during adolescence.

Our first research question involved checking whether the social rank scales (social comparison and submissive behavior) predicted depression symptoms in our integrated model. As expected, our results showed that both the social comparison and the submissive behavior scales play a significant role. This supports the results of Irons and Gilbert (2005) regarding the relationship between social rank and depressive symptoms in an adolescent population, and the study of Öngen (2006) regarding the relevance of submissive behavior in the prediction of depressive symptoms in high school students. These results illustrate the importance of the perception of adolescents in relation to their rank within their group of peers. Moreover, a significant interaction was found between both social rank scales. This interaction suggests that when the adolescent compares himself negatively with others (i.e., through feelings of inferiority), submissive behavior is involuntary and forced upon the adolescent in an attempt to be accepted by others. As stated by the social rank theory, this involuntary submission on top of poor support may contribute to the development of depression (Gilbert, 2000). On the other hand, when the adolescent compares himself positively with others, submissive behavior could be voluntary, thereby not necessarily influencing the development of depression.

Our second research question involved evaluating the relative contribution of the quality of attachment to the mother to the father or to peers (as measured by the IPPA scales) to the prediction of depressive symptoms in our integrated model. We found that only the quality of attachment to the father and to the mother plays a significant role. However, the effect of the quality of attachment to the father $(p<$ $.00)$ seems to be stronger than the effect of the quality of attachment to the mother $(p=.04)$. This is in line with the results of Liu (2008), who found that attachment to the father predicted friends support, peer expectations, self-worth and depressive symptoms better than attachment to the mother.

Some studies (e.g., Lieberman, Doyle, \& Markiewicz, 1999) suggest that the availability of the father in play interactions during childhood might contribute to the learning of emotion regulation. However, during adolescence the father is perceived by girls as being less available in contrast to the maternal availability, which remains constant during middle childhood and adolescence. The apparent lack of availability of the father, on top of his relative importance in the development of social skills and emotion regulation, could explain the strong role of the quality of attachment to the father in determining the depressive symptoms in our sample. Further studies that relate the quality of attachment to the father and its specific components to depression are needed.

Our third research question involved evaluating how the different styles of peer attachment (secure, ambivalent and avoidant) are related to depression in our integrated model. Just as for the quality of attachment to peers, the style of attachment towards peers does not play a significant role in predicting depression. However, the mediation analysis suggests that the effect of the peer attachment scales might be mediated by the social rank scales. These findings suggest that the development of satisfactory relationships with peers results in a good functioning of the dominance and subordination systems (social rank) (Cooper et al., 1998; Wilkinson, 2004). Therefore, adolescents characterized by a striving for selfacceptance by gaining the acceptance of valued others (ambivalent attachment, Bartholomew \& Horowitz, 1991) will be in his/her relationship with others, overly focused on social comparisons, worried about rejection and adopting submissive strategies. This is in line with the work of Irons and Gilbert (2005) and of Allen et al., (1998). They found that the effect of some aspects of attachment organization (i.e., security but not preoccupation) in the prediction of internalizing behaviors disappeared after accounting for factors such as the adolescent's perceived self-worth. This suggests that insecurity related to internalized behaviors overlaps with an individual's perceived low self-worth. 
On the other hand, the avoidant attachment style towards peers was not mediated by the social rank variables. The avoidant attachment style is characterized by pushing peers away (Bauminger, Finzi-Dottan, Chason, \& Har-Even, 2008) and by minimizing the need for others (Brown \& Wright, 2003). This style uses a deactivation strategy to regulate deployment and emotion, thereby minimizing personal vulnerability and the need for support (Cole-Detke \& Kobak, 1996). Therefore, not having any social contact might be more protective against depression than adopting, for example, the ambivalent attachment style.

Our final research question involved checking whether sex and age remained important predictors in our integrated model. According to the literature, we should find a significant sex difference (with girls having a higher level of depression than boys) and a significant interaction between sex and age, since the level of depression remains more or less constant for boys, but increases strongly for girls (e.g., Ge et al., 1994). In our study, we found that sex and age were indeed significant (with girls attaining a higher level of depression than boys and depressive levels increasing on average as age increases), but that the interaction between age and sex was not significant. This is probably due to a lack of power in our study. Moreover, as pointed out by the mediation analysis, a part of the effect of sex seems to be mediated by social comparison and submissive behavior, since girls have on average a more negative social comparison and a higher level of submissive behavior than boys. This is in accordance with the idea that girls are more vulnerable to interpersonal stress (Nolen-Hoeksema, 2001), which may explain the observed gender differences in depression present in our integrated model. Another interesting result was the significant interaction between age and the quality of attachment to the mother. This interaction seems to support the general idea that the mother is important during early adolescence but that the importance of the mother's role in predicting depressive symptoms weakens as the adolescent becomes older.

By integrating the above results, our model suggests that a poor quality of attachment towards the father and mother, together with a negative social comparison and a submissive behavior will predict depressive symptoms during adolescence. Parental attachment and the social rank systems complement each other and operate in an independent manner, since no interactions were found between any of the parental quality of attachment scales and any of the social rank scales. Furthermore, social rank variables mediate peer attachment. This means that valorization by others is very important during adolescence for the individual's self-worth and therefore acceptance by the group constitutes a priority for an adolescent. This can force the individual to adopt strategies for being accepted, through exhibiting submissive behavior, and will therefore determine how he/she relates to his/her peers. As such, when the adolescent needs to deal with particular interpersonal stress events (to which girls are more vulnerable), a low self-esteem and a constant negative social comparison together with a low level of support from significant others (parents) will lead to reactions characterized by negative emotions. These negative emotions will be more intense and persistent if an involuntary submissive behavior is established.

Our study has several limitations; the main limitation relates to the small sample size, which did not allow us to perform more sophisticated analyses, such as a Structural Equation Model. The generalizability of the results of our study might be questionable, since it consisted of a high percentage of girls and third year secondary school students. Furthermore, our integrated model only included the scale of attachment styles towards peers; an extension of our model could be constructed by also including the different attachment styles towards the mother and the father and by including the other subtype identified in Bartholomew's work (Bartholomew \& Horowitz, 1991). In addition, results were only taken from a single source (participant), using a single method (self-report) at a single time (crosssectional).

In conclusion, this study clearly shows that social rank variables (social comparison and submissive behavior), attachment variables (overall quality of attachment to the father and to the mother), age and sex are important in predicting depressive symptoms during adolescence. Moreover, this is the first study that tentatively investigates the role of attachment to the father, to the mother and to peers and social rank in an integrated model in relation to depressive symptoms during adolescence. Furthermore, it suggests, as Sloman observed, that these aspects may have a complementary relationship, and that dysfunction in the attachment and social rank systems could be related to the presence of depression, since both factors are involved in the regulation of affect (Sloman et al., 2003; Sloman, 2008). A future comparable study needs to be performed on clinically depressed adolescents

\section{References}

Ainsworth, M. D. S., Blehar, M. C., Waters, E., \& Wall, S. (1978). Patterns of attachment. A psychological study of the strange situation. Hillsdayle, NJ: Lawrence Erlbaum Associates.

Allen, J. P., Moore, C., Kuperminc, G., \& Bell, K. (1998). Attachment and adolescent psychosocial functioning. Child Development, 69, 1406-1419. doi:10.1111/j.1467-8624.1998.tb06220.x

Armsden, G. C., \& Greenberg, M. T. (1987). The Inventory of Parent and Peer Attachment: Individual differences and their relationship to psychological well-being in adolescence. Journal of Youth and Adolescence, 16, 427-454. doi:10.1007/BF02202939

Aslund, C., Nilsson, K. W., Starrin, B., \& Sjöberg, R. L. (2007). Shaming experiences and the association between adolescent depression and psychosocial risk factors. European Child \& Adolescent Psychiatry, 16, 298-304. doi:10.1007/s00787-006-0564-1 
Bauminger, N., Finzi-Dottan, R., Chason, S., \& Har-Even, D. (2008). Intimacy in adolescent friendship: the roles of attachment, coherence, and self-disclosure. Journal of Social and Personal Relationships, 25, 409-428. doi:10.1177/0265407508090866

Bartholomew, K., \& Horowitz, L. M. (1991). Attachment styles among young adults: a test of a four-category model. Journal of Personality and Social Psychology, 61, 226-244. doi:10.1037/0022-3514.61.2.226

Bowlby, J. (1969). Attachement et perte [Attachment and loss] (Vol. I). Paris, France: J. Presses universitaires de France.

Brown, L. S., \& Wright, J. (2003). The relationship between attachment strategies and psychopathology in adolescence. Psychology and Psychotherapy: Theory, Research and Practice, 76, 351-367. doi:10.1348/147608303770584728

Chabrol, H., Montovany, A., Chouicha, K., Duconge, E., Massot, E., \& Kallmeyer, A. (2002). Étude de la CES-D dans un échantillon de 1953 adolescents scolarisés [Study of the CES-D on a sample of 1953 high-school students]. L'Encéphale, 28, 429-432.

Chabrol, H., Rodgers, R., \& Rousseau, A. (2007). Relations between suicidal ideation and dimensions of depressive symptoms in high-school students. Journal of Adolescence, 30, 587-600. doi:10.1016/j.adolescence.2006.07.003

Cole-Detke, H., \& Kobak, R. (1996). Attachment processes in eating disorder and depression. Journal of Consulting and Clinical Psychology, 64, 282-290. doi:10.1037/0022-006X. 64.2.282

Cooper, M. L., Shaver, P. R., \& Collins, N. L. (1998). Attachment styles, emotion regulation and adjustment in adolescence. Journal of Personality and Social Psychology, 74, 1380-1397. doi:10.1037/0022-3514.74.5.1380

Dekovic, M., \& Meeus, W. (1997). Peer relations in adolescence: effects of parenting and adolescents' self-concept. Journal of Adolescence, 20, 163-176. doi:10.1006/jado.1996.0074

Doyle, A. B., Lawford, H., \& Markiewicz, D. (2009). Attachment style with mother, father, best friend, and romantic partner during adolescence. Journal of Research on Adolescence, 19, 690-714. doi:10.1111/j.1532-7795.2009.00617.x

Duchesne, S., \& Larose, S. (2007). Adolescent parental attachment and academic motivation and performance in early adolescence. Journal of Applied Social Psychology, 37, 1501-1521. doi:10.1111/j.1559-1816.2007.00224.x

Eskin, M., Ertekin, K., Harlak, H., \& Dereboy, C. (2008). Prevalence of and factors related to depression in high school students. Turkish Journal of Psychiatry, 19(4), 1-8.

Ge, X., Lorenz, F. O., Conger, R. D., Elder, Jr. G. H., \& Simons, R. (1994). Trajectories of stressful life events and depressive symptoms during adolescence. Developmental Psychology, 30, 467-483. doi:10.1037/0012-1649.30.4.467

Gilbert, P. (2000). The relationship of shame, social anxiety and depression: the role of the evaluation of social rank. Clinical Psychology and Psychotherapy, 7, 174-189. doi:10.1002/10990879(200007)7:3<174::AID-CPP236>3.0.CO;2-U

Gilbert, P., \& Allan, S. (1994). Assertiveness, submissive behaviour, and social comparison. British Journal of Clinical Psychology, 33, 295-306.
Gilbert, P., Allan, S., \& Trent, D. R. (1995). Involuntary subordination or dependency as key dimensions of depressive vulnerability? Journal of Clinical Psychology, 51, 740-752. doi:10.1002/10974679(199511)51:6<740::AID-JCLP2270510604>3.0.CO;2-\#

Hankin, B. L. (2006). Adolescent depression: description, causes, and interventions. Epilepsy \& Behavior, 8, 102-114. doi:10.1016/j.yebeh.2005.10.012

Hazan, C., \& Shaver, P. (1987). Romantic love conceptualized as an attachment process. Journal of Personality and Social Psychology, 52, 511-524. doi:10.1037/0022-3514.52.3.511

Irons, C., \& Gilbert, P. (2005). Evolved mechanisms in adolescent anxiety and depression symptoms: the role of the attachment and social rank systems. Journal of Adolescence, 28, 325341. doi:10.1016/j.adolescence.2004.07.004

Laible, D. (2007). Attachment with parents and peers in late adolescence: links with emotional competence and social behavior. Personality and Individual Differences, 43, 11851197. doi:10.1016/j.paid.2007.03.010

Leary, M. R. (2003). Commentary on self-esteem as an interpersonal monitor: the sociometer hypothesis (1995). Psychological Inquiry, 14, 240-274. doi:10.1207/S15327965PLI 1403\&4 15

Leyva-Jiménez, R., Hernández-Juárez, A. M., Nava-Jiménez, G., \& López-Ganoa, V. (2007). Depresión en adolescentes y funcionamiento familiar [Depression in adolescents and family functioning]. Revista Médica del Instituto Mexicano del Seguro Social, 45, 225-232.

Lieberman, M., Doyle, A. B., \& Markiewicz, D. (1999). Developmental patterns in security of attachment to mother and father in late childhood and early adolescence: Associations with peer relations. Child Development, 70, 202-213. doi:10.1111/1467-8624.00015

Liu, Y. L. (2008). An examination of three models of the relationships between parental attachments and adolescents' social functioning and depressive symptoms. Journal of Youth and Adolescence, 37, 941-952. doi:10.1007/s10964-006-9147-1

Margolese, S. K., Markiewicz, D., \& Doyle, A. B. (2005). Attachment to parents, best friend and romantic partner: predicting different pathways to depression in adolescence. Journal of Youth and Adolescence, 34, 637-650. doi:10.1007/ s10964-005-8952-2

Nickerson, A. B., \& Nagle, R. J. (2005). Parent and peer attachment in late childhood and early adolescence. Journal of Early Adolescence, 25, 223-249. doi:10.1177/0272431604274174

Nolen-Hoeksema, S. (2001). Gender differences in depression. Current Directions in Psychological Science, 10, 173-176. doi:10.1111/1467-8721.00142

Öngen, D. E. (2006). The relationships between self-criticism, submissive behavior and depression among Turkish adolescents. Personality and Individual Differences, 41, 793-800. doi:10.1016/j.paid.2006.03.013

Radloff, L. S. (1977). The CES-D Scale: A self-report depression scale for research in the general population. Applied Psychological Measurement, 1, 385-401. doi:10.1177/0146621 67700100306 
Rigby, K., Slee, P. T., \& Martin, G. (2007). Implications of inadequate parental bonding and peer victimization for adolescent mental health. Journal of Adolescence, 30, 801812. doi:10.1016/j.adolescence.2006.09.008

Rushton, J. L., Forcier, M., \& Schetman, R. M. (2002). Epidemiology of depressive symptoms in the national longitudinal study of adolescent health. Journal of the American Academy of Child and Adolescent Psychiatry, 41, 199-205. doi:10.1097/00004583-200202000-00014

Sharpe, T. M., Killen, J. D., Bryson, S. W., Shisslak, C. M., Estes, L. S., Gray, N., ... Taylor, C. B. (1998). Attachment style and weight concerns in preadolescent and adolescent girls. International Journal of Eating Disorders, 23, 39-44. doi:10.1002/(SICI)1098108X(199801)23:1<39::AID-EAT5>3.0.CO;2-2

Sloman, L. (2008). A new comprehensive evolutionary model of depression and anxiety. Journal of Affective Disorders, 106, 219-228. doi:10.1016/j.jad.2007.07.008

Sloman, L., Gilbert, P., \& Hasey, G. (2003). Evolved mechanisms in depression: the role and interaction of attachment and social rank in depression. Journal of Affective Disorders, 74, 107121. doi:10.1016/S0165-0327(02)00116-7

Stevens, A., \& Price, J. (2000). Evolutionary Psychiatry. A new beginning ( $2^{\text {nd }}$ ed.). Philadelphia, PA: Brunner-Routledge,
Taylor\&Francis Group.

Sund, A. M., \& Wichstrom, L. (2002). Insecure attachment as a risk factor for future depressive symptoms in early adolescence. Journal of the American Academy of Child and Adolescent Psychiatry, 41, 1478-1485. doi:10.1097/00004583-20021200000020

Wilkinson, R. B. (2004). The role of parental and peer attachment in the psychological health and self-esteem of adolescents. Journal of Youth and Adolescence, 33, 479-493. doi:10.1023/ B:JOYO.0000048063.59425.20

World Head Organization (2005). La santé des enfants et adolescents en Europe [Children's and adolescents' health in Europe]. Aide Mémoire EURO/06/05. Retrieved from http://www.euro.who.int/ en/home

Young, J. F., Berenson, K., Cohen, P., \& Garcia, J. (2005). The role of parent and peer support in predicting adolescent depression: a longitudinal community study. Journal of Research on Adolescence, 15, 407-423. doi:10.1111/j.15327795.2005.00105.x

Received April 19, 2010 Revision received November 9, 2010 Accepted December 16, 2010 